\title{
A Criação de Novidades na Ação de Projetar Ambientes Virtuais de Aprendizagem: um estudo de caso com o NUTED/UFRGS
}

\author{
Prof $^{a}$ Dr $^{\mathrm{a}}$. Sílvia Meirelles Leite (UFPEL) - silviameirelles@gmail.com \\ Prof $^{a}$ Dra $^{\mathrm{a}}$. Patricia Alejandra Behar (UFRGS) - pbehar@terra.com.br \\ Prof ${ }^{a}$ Dra $^{\mathrm{a}}$. Maria Luiza Becker (UFRGS) - mlbecker@portoweb.com.br
}

\begin{abstract}
Resumo: O presente estudo analisa a relação entre a construção de formalizações e a criação de novidades na ação de projetar Ambientes Virtuais de Aprendizagem (AVAs). Para tanto, busca-se subsídios na teoria piagetiana, enfocando o jogo entre forma e conteúdo a parir das relações entre as propriedades do objeto. Tal abordagem converge para a construção de estruturas formais nos projetistas e de formalizações nos projetos, tendo como premissa uma perspectiva interdisciplinar. A fim de compreender esse processo, propõe-se um estudo de caso com o grupo de pesquisa NUTED/UFRGS. Com isso, reflete-se sobre a produção de materiais destinados à Educação a Distancia (EAD), tendo em vista que essa é uma prática cada vez mais presente nas instituições de ensino. Palavras-chave: criação de novidades, ambiente virtual de aprendizagem, interdisciplinaridade
\end{abstract}

Abstract: This study examines the relationship between the construction of formalization and the creation of novelty in the design action of Virtual Learning Environments. Subsidies in Piagetian theory was search, focusing on the interplay between form and content from relations between the object properties. This approach converges to the formal structures construction in the designers and projects formalization, taking an interdisciplinary perspective as premise. To understand this process, we propose a case study with the NUTED/UFRGS research group. With that, reflects on the materials production for the Distance Education (EAD), this practice is increasingly present in educational institutions.

Keywords: creation of novelty, learning virtual environment, interdisciplinarity.

\section{Introdução}

O presente artigo discute a Criação de Novidades na ação de projetar Ambientes Virtuais de Aprendizagem (AVA), tendo como referencial teórico-metodológico a teoria piagetiana. Este estudo é um recorte da Tese de Doutorado de Leite (2008), que investiga o engendramento da interdisciplinaridade na ação de projetar AVA's e que propõe um estudo de caso com o Núcleo de Tecnologia Digital aplicada à Educação (NUTED) da Universidade Federal do Rio Grande do Sul (UFRGS). Neste enfoque, elucidam-se as relações entre as formalizações no projeto e a criação de novidades para os projetistas e para a equipe que projeta o AVA.

De acordo com a perspectiva piagetiana adotada nesse estudo, a criação de novidades na ação de projetar é caracterizada pelo processo de abstração reflexionante, de modo que os projetistas realizam coordenações de operações, combinando elementos retirados do objeto de estudo e identificando novos observáveis (Piaget, 1995). A partir disso, pode-se observar as integrações e as diferenciações realizadas pelos projetistas, bem como os desequilíbrios oriundos da identificação de novos observáveis. Entende-se que para analisar a criação de novidades em projetos interdisciplinares de AVA, é preciso observar a mudança de conduta na execução do projeto, o que requer que se 
elucide como o objeto de estudo foi formalizado e quais as novidades que foram criadas.

Para subsidiar a cientificidade do Estudo de Caso, esta pesquisa baseia-se em Yin (2005). De acordo com o autor, o estudo de caso opera a partir de problemas de pesquisa baseados em "Como?" e "Por quê?", o que vai ao encontro da perspectiva teórico-metodológica da teoria piagetiana. Logo, define-se como questão central desse estudo: Como se constitui a criação de novidades na ação de projetar Ambientes Virtuais de Aprendizagem nos projetos do NUTED/UFRGS?

\section{A Criação de Novidades e o Jogo entre Forma e Conteúdo}

A ação de projetar AVAs comporta a articulação entre conhecimentos científicos, experiências pessoais dos projetistas e as interações entre os projetistas envolvidos e destes com o objeto de estudo (o AVA). Ou seja, são realizadas coordenações de ações caracterizadas pelo jogo entre forma e conteúdo, no qual os sujeitos envolvidos estabelecem relações entre os observáveis apontados e constroem formalizações. Tal enfoque tem como subsídio uma leitura piagetiana sobre construção de conhecimentos e as transformações que caracterizam o desenvolvimento científico e tecnológico.

Piaget $(1995,1976)$ estudou os mecanismos que caracterizam essa construção de conhecimento, enfocando a passagem de um estado de equilíbrio provisório, para um desequilíbrio e um novo equilíbrio. Para o autor a atividade cognitiva consiste na superação e na inovação continuada, o que é subsidiado por um mecanismo autoregulador, o qual agrega complementações, correções e novas problematizações. Logo, a mudança estrutural concernente à criação de novidades requer operações recíprocas que compensam e complementam inconsistências, trabalhando com a estabilidade do que foi adquirido e com necessidade de superação por parte do sujeito. Para compreender esse mecanismo de construção de novas estruturas nos processos cognitivos volta-se à abstração reflexionante como criadora de novidades.

De acordo com o Piaget (1995), através da abstração o sujeito retira as propriedades de estruturas inferiores para combiná-las em estruturas mais alargadas e superiores, que, por sua vez, são mais elaboradas. A abstração reflexionante apoia-se sobre as coordenações que o sujeito realiza, alcançando a construção de estruturas intemporais. A criação de novidades derivada da abstração reflexionante tem como base o processo geral de equilíbrio, o qual está vinculado à idéia de totalidade e de provisoriedade. Ou seja, existe um equilíbrio provisório entre as partes e o todo, de modo que as propriedades estão subordinados a uma regra geral. Por outro lado, os desequilíbrios cognitivos também constituem esse processo de reorganização estrutural, sendo que a novidade está na superação desses desequilíbrios por meio de reequilibrações. Portanto, a criação de novidades comporta a construção de novos conhecimentos dentro de uma perspectiva de evolução em formato de espiral, no qual os patamares inferiores são reorganizados em um patamar superior através de um jogo entre forma (coordenações) e conteúdo (observáveis).

A construção de formalizações caracteriza a criação de novidades na ação de projetar AVAs, configurando a construção da totalidade do projeto, de modo que são estabelecidas relações entre as partes (propriedades do projeto) e o todo (o próprio projeto), o que está subordinado às leis que regem o projeto. Essas leis são construídas a partir das coordenações dos observáveis, o que acarreta as escolhas das propriedades e dos procedimentos de composição do projeto. Além disso, o projeto apresenta conservação dos conteúdos e formalizações precedentes e transformações decorrentes das novas relações. Isso implica a diferenciação e a integração dos observáveis através 
de coordenações de ações, ou seja, os projetistas precisam evidenciar o que é igual e o que é diferente nos recursos e na maneira de manipulá-los.

Ao tratar sobre a ação de projetar, buscam-se referências em Piaget (1985) e Oliveira (2007, 2004) para analisar como os sujeitos estabelecem composições e realizam escolhas acerca dos procedimentos adotados. Com isso, vislumbram-se as possibilidades que o material oferece, implicando a construção de relações e a transposição de observáveis físicos. Tal enfoque ressalta a configuração de projeto através da integração entre as regras formais e o sistema de significação, sendo que as escolhas desse âmbito são evidenciadas na materialidade do AVA. A ação de projetar contempla uma produção documental e a coordenação de ações concernentes à delimitação de um objetivo e dos meios para alcançá-lo.

Nesse processo são realizadas generalizações e formalizações, que se apoiam nas operações dos projetistas e nas propriedades elencadas para o AVA. Essas formalizações podem ser retomadas e reelaboradas, o que é subsidiado por analogias com experiências anteriores e reconstruções com novos conteúdos. Ou seja, é uma ação recursiva e majorante, quanto mais ocorrem interações entre os projetistas e o projeto, mais se identificam novos observáveis e se constroem novas relações. Quando o projetista aponta um novo observável e o incorpora ao projeto, é preciso identificar se a formalização construída comporta esse novo conteúdo, o que pode levar a desequilíbrios. Com isso, remete-se à totalidade do projeto e à conservação das relações e das escolhas anteriores, num jogo entre o que está sendo assimilado pelo projetista e o que está sendo incorporado ao projeto.

Na delimitação do objeto de estudo do projeto se definem quais os recursos serão disponibilizados no AVA, no que eles se diferenciam e no que eles convergem para um mesmo ponto. Também se elucidam em quais aspectos as atividades dos projetistas se diferenciam e quais atividades exigem uma coordenação integrativa das diferentes abordagens. Para analisar a criação de novidades em projetos interdisciplinares de AVA, é preciso observar a mudança de conduta na execução do projeto, o que requer que se elucide como o objeto de estudo foi formalizado e quais as novidades que foram criadas.

\section{O Estudo de Caso do NUTED/UFRGS}

A fim de ampliar o debate sobre a ação de projetar AVAs, foi realizado um estudo de caso com o NUTED/UFRGS, um grupo de pesquisa que trabalha com 0 desenvolvimento e a utilização de tecnologias digitais aplicadas à educação. Mais detalhes sobre o NUTED/UFRGS podem ser encontrados em www.nuted.edu.ufrgs.br.

A equipe do NUTED agrega projetistas de diferentes áreas do conhecimento, com destaque para a Pedagogia, a Comunicação Social, a Informática e o Design. Dentre as linhas de pesquisa desse grupo, ressalta-se a denominada Ambientes Virtuais de Aprendizagem (AVA), na qual estão inseridos os projetos: 1) ROODA (Rede cOOperativa De Aprendizagem), um AVA utilizado no Ensino Superior disponível em www.ead.ufrgs.br/rooda; 2) o PLANETA ROODA, um AVA voltado a alunos e professores do Ensino Fundamental disponível em www.nuted.edu.ufrgs.br/rooda, e 3) o ETC (Editor de Texto Coletivo), um AVA voltado à escrita coletiva disponível em www.nuted.edu.ufrgs.br/etc. Esses projetos foram realizados por projetistas que estão divididos nos subgrupos: da Educação (PE), do Design (PD) e da Programação (PP).

Esse estudo enfoca o período entre julho de 2003 e novembro de 2006, o qual compreende as etapas de planejamento, implementação e avaliação de versões dos três 
AVAs citados. Para analisar a criação de novidades no projeto do NUTED/UFRGS e coletar os dados dessa pesquisa, adotou-se três unidades de análise, que são: o sistema de significações, os valores coletivos de troca e as regras formais. De acordo com Piaget (1976; 1973), o sistema de significações compõe a linguagem usada na ação de projetar, de modo que ele constitui um meio de expressão que serve para comunicar as regras e os valores. Os valores coletivos compreendem tudo o que pode dar vez a uma troca, desde os objetos presentes na ação prática até as idéias e representações presentes numa troca. As regras trazem para o debate certa consciência de obrigação entre os projetistas, o que pode ser vislumbrado nas regulações das trocas entre os projetistas e nas formalizações do projeto.

A coleta de dados foi realizada em quatro fontes de evidência: 1) as entrevistas focais com os projetistas, 2) as figuras dos projeto, 3) os registros documentais e 4) a observação participante. De acordo com Yin (2005), com a observação participante é possível compartilhar de situações inacessíveis a observadores externos, de modo que se tem acesso a informações e eventos habituais e/ou de domínio privado. Com isso, foi possível vislumbrar questões referentes ao contexto da pesquisa e conciliá-las com os dados coletados nas outras fontes de evidência.

\subsection{A Criação de Novidades nas Entrevistas}

Através da Coleta de Dados nas entrevistas vislumbrou-se as reflexões dos projetistas sobre a elaboração dos projetos ROODA, PLANETA ROODA e ETC. Ao todo foram 17 entrevistas, divididas entre Projetistas da Educação (PE), do Design (PD) e da Programação (PP). Os critérios usados para escolher quem seria entrevistado foram: a efetiva colaboração no projeto e ter participado de três ou duas etapas do processo de construção dos AVA's. A maioria dos entrevistados participaram de dois projetos, ROODA e ETC ou ROODA e PLANETA ROODA, o que possibilitou observar como as aprendizagens e as formalizações construídas no decorrer da ação de projetar o ROODA foram reelaboradas nos projetos subsequentes.

O entendimento sobre as coordenações de operações realizadas pelos projetistas e a identificação de novos observáveis elucida a perspectiva de que o objeto de estudo nunca se esgota, pois na ação de projetar são trazidas novas questões que levam a problematizar as decisões e as formalizações referentes ao AVA. Tal enfoque é visibilizado nas entrevistas dos projetistas, como observa-se no trecho abaixo de PESuj02, quando ele responde sobre a organização do grupo para projetar o AVA.

PE-Suj02: Primeiro a gente precisa saber tudo que a gente quer para esse ambiente. Quando a gente pensa ele em âmbito geral, a gente vai montando os recursos em particular. Depois como esses recursos vão se comunicar. Quando a gente pensa esses recursos a gente ta falando de uma gama de elementos, porque a gente vai ter que ver a viabilidade de programação, de usabilidade, de interface, na operacionalização desse recurso. Cada elemento tem alguns caminhos que a gente tem que ter pesquisado, volta com todas as informações e organiza ele dentro do todo. A partir dessa discussão dos elementos, que outros elementos não foram pensados naquela primeira estrutura vão sendo agregados.

\section{Evidência 1: Trecho da Entrevista do PE-Suj02}

A partir dessa evidência, enfoca-se a compreensão da ação de projetar por parte dos projetistas, bem como o estabelecimento de relações entre o que está sendo observado e como isso é reconstruído no projeto de AVA. De acordo com o PE-Suj02, 
isso implica um entendimento do que se quer para o ambiente, quais as particularidades dos recursos e como eles vão se comunicar. O levantamento destes elementos (propriedades do projeto) agrega pesquisa e debates, o que pode reverberar para a observação de elementos que não haviam sido pensados anteriormente. Entende-se que os elementos pesquisados e debatidos remetem aos momentos de regulações entre os observáveis, abrindo possibilidades para novas regulações e para a criação de relações entre os elementos observados. Assim, tem-se construção de conhecimento no que diz respeito ao projeto e à maneira do grupo se organizar para elaborá-lo. Este novo conhecimento abarca uma totalidade que se configura na ação de relacionar os observáveis, como os citados por PE-Suj02, que podem versar sobre: viabilidade de programação, usabilidade, interface e vantagens para a educação.

Logo, a ação de projetar contempla o estabelecimento de relações entre partes e todo, confluindo para uma reorganização da equipe e do objeto de estudo. Destaca-se a relação dialética que existe neste processo, de modo que quanto mais a equipe organiza o objeto de estudo, mais ela se organiza, e vice-versa. Para entender esse decurso, recorre-se à abstração reflexionante que, retira propriedades de um determinado objeto e estabelece relações entre elas. Com isso, podem-se observar transformações e equilíbrios provisórios.

\subsection{A Criação de Novidades nas Telas dos Projetos}

As figuras dos projetos analisadas foram as telas construídas e debatidas durante 0 processo de planejamento dos AVAs e os organogramas que subsidiam a implementação do artefato. Através dessas figuras, buscou-se vislumbrar as transformações do projeto, tanto nas formalizações quanto nas propriedades indicadas para o artefato. De acordo com Oliveira (2007, 2004), as figuras de um projeto caracterizam-se por serem objetos conceituais, pois são mensuráveis e formalizadas, exteriorizando o caráter construtivo do objeto do conhecimento. Portanto, apesar da figura ser diferente do artefato em sua composição material, ambos obedecem a uma mesma lógica compositiva. Com as figuras podem-se observar as construções dos projetistas em torno do objeto de estudo e as coordenações lógicas construídas.

A ação de projetar AVAs comporta a diferenciação de conteúdos e a correspondência entre ações, configurando a assimilação dos objetos entre si e possibilitando a elaboração de conceitos enquanto classe. Este processo pode ser visualizado na construção da hierarquia de navegação do AVA, delineando os caminhos que o usuário pode percorrer para acessar determinado recurso e no que isso interfere no modelo conceitual. Essa construção impele a criação de um modelo explicativo, o que requer a compreensão do modelo conceitual e das possíveis ações dos usuários. Em vista disso, para sua implementação, os projetistas precisam compor uma figura que apresente as regras lógicas que constituem o AVA. Portanto, compõe-se uma totalidade que agrega as diferenciações entre os elementos que constituem a figura e sistemas de regras lógicas. Tal processo pode ser vislumbrado na Evidência 2, que apresenta a estrutura da hierarquia de navegação do PLANETA ROODA. 


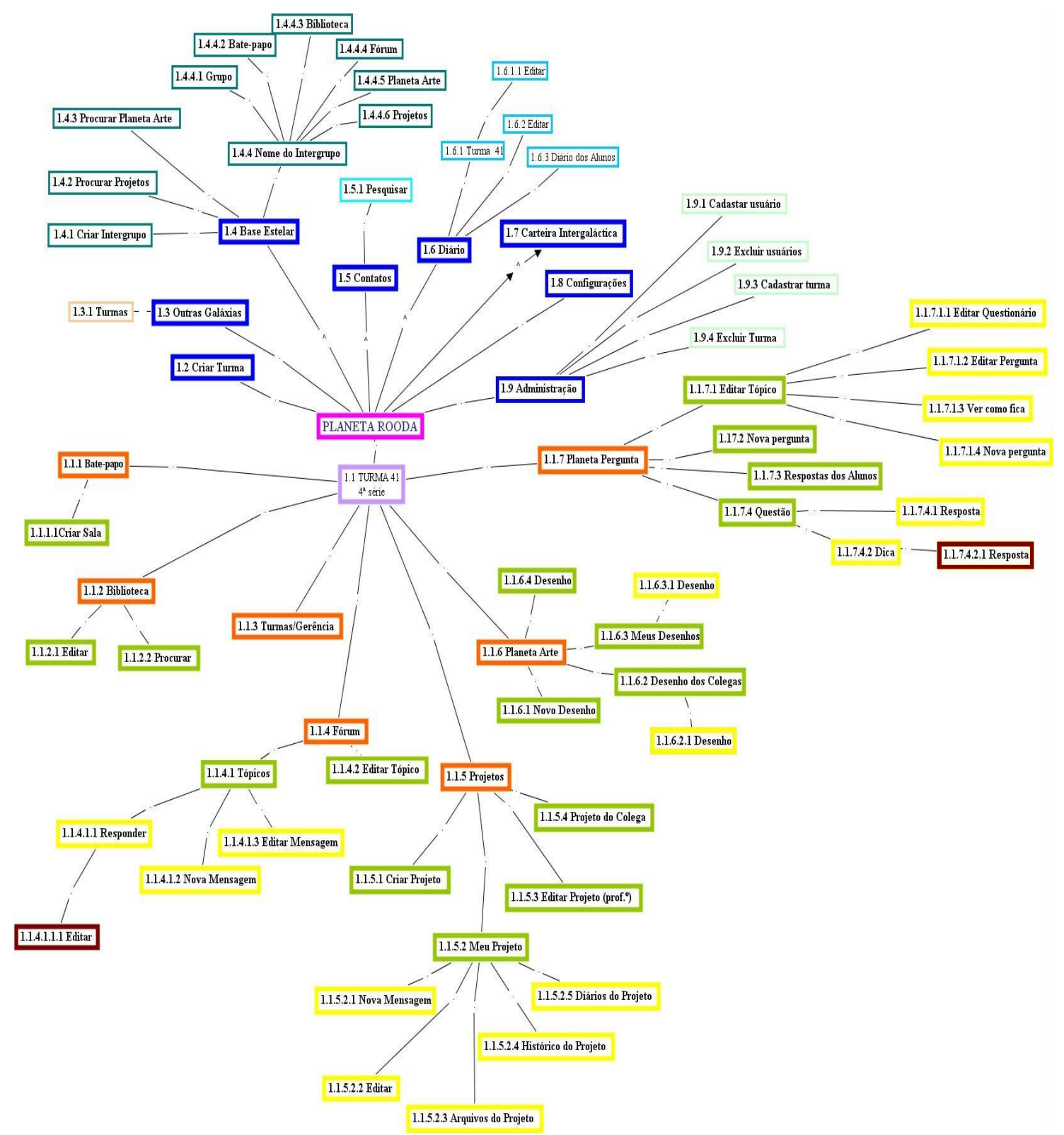

Evidência 2: Figura da Hierarquia de Navegação do PLANETA ROODA

A hierarquia de navegação de uma AVA traz um mapeamento dos possíveis caminhos e um ordenamento dos elementos visuais, visando facilitar o acesso a uma informação e destacar os elementos que a compõem. Dentre os elementos delimitados pelos projetistas para compor a Evidência 2, destaca-se: a utilização de cores para distinguir as funcionalidades gerais das específicas e os diferentes níveis hierárquicos, localização central da primeira tela de acesso e a possibilidade de posteriormente inserir outras funcionalidades e outras telas. Com isso, enfatizam-se os níveis de ordenamento dos elementos visuais, elucidando os possíveis caminhos que os usuários podem percorrer e o número de cliques para se chegar ao recurso desejado. Para construir essa figura, os projetistas precisaram trabalhar no plano hipotético-dedutivo e coordenar as sucessões de ações possíveis.

Esse processo de construção de uma figura de hierarquia de navegação subsume os observáveis empíricos, que são derivados do que se debateu para o projeto do AVA e das experiências pessoais como usuários de softwares para web e as pesquisas sobre 
outros usuários. Estes observáveis são coordenados em uma totalidade que relaciona os elementos a partir das regras lógicas que regem o projeto, antecipando e subsidiando a materialização do artefato. Portanto, vislumbra-se a construção de um objeto conceitual, no qual se trabalha com a compreensão dos processos e com as diferenciações e integrações (destacadas pelas cores). Através da cor é possível identificar se as telas estão no mesmo nível de hierarquia ou não e pelas linhas é possível delimitar o percurso a ser percorrido para acessar o recurso de uma funcionalidade específica.

A primeira regra lógica que rege essa figura de hierarquia de navegação do PLANETA ROODA é a diferença entre as funcionalidades específicas (destacadas pela cor vermelha) e as funcionalidades gerais (destacadas pela cor azul escuro). A partir dessa classificação são construídas subclasses referentes aos níveis de ordenamento na hierarquia, que também são destacadas por outras cores. Tal situação pode ser exemplificada pelas funcionalidades específicas "Projetos" e "Fórum”, ambas estão destacadas pela cor vermelha por estarem no mesmo nível hierárquico, ou seja, para acessá-las é preciso: 1) entrar no PLANETA ROODA, 2) clicar na turma desejada, 3) clicar numa das funcionalidades disponíveis, 4) escolher um dos recursos dessas funcionalidades. Este percurso é delineado pelas linhas que apontam o caminho necessário para acessar o que se deseja, ordenando uma série de classes e subclasses. Ou seja, a linha aponta as relações dentro do percurso que o usuário pode percorrer e a cor remete às relações de nível hierárquico. Desse modo, a cor lilás pode referir às diferentes turmas em que o usuário está cadastrado, a cor vermelha refere-se às funcionalidades específicas vinculadas na turma (como fórum e projetos), a cor verde aos recursos de primeiro nível (como os tópicos do fórum), a cor amarela aos recursos de segundo nível (como o responder a mensagem de um tópico de fórum) e a cor marrom remete a um recurso de terceiro nível (como a edição de uma resposta publicada num tópico de um fórum). Com isso, pode-se vislumbrar a coordenação integrativa de propriedades, o que é regido pelas regras lógicas que engendram o AVA.

Entende-se que a composição de figuras para um projeto interdisciplinar de AVA agrega uma criação de novidades para o projeto e para os projetistas, pois se trabalha com a atribuição de propriedades para os elementos e com a coordenação dessas propriedades. Diante disso, tem-se a construção de um objeto do conhecimento conceitual, que ultrapassa o nível concreto e apresenta operações de conteúdos articulados em uma formalização intemporal. Para tanto, são delimitadas diferenças e semelhanças entre os conteúdos, que são classificados e seriados com base nas regras lógicas construídas para o projeto. Ao mesmo tempo, esse processo elucida novos observáveis, contribuindo para que os projetistas reflitam sobre as regras formalizadas.

\subsection{A Criação de Novidades nos Registros Documentais}

No que tange aos registros documentais dos projetos, foram analisadas as atas das reuniões, os formulários de avaliação usados para os três AVAs e as anotações pessoais dos projetistas. Nesses registros, buscaram-se evidências que elucidassem as decisões e as regras estabelecidas na ação de projetar, tanto no que se refere ao objeto de estudo quanto aos procedimentos de trabalho adotados pelas equipes. Os arquivos com esses registros estavam salvos na rede interna do NUTED, sendo que o acesso a esses arquivos possibilitava que os projetistas consultassem as decisões anteriores e refletissem sobre o que estava sendo argumentado, potencializando mais objetividade e coerência nas contribuições e nas resoluções.

Nesta perspectiva, destaca-se uma solidariedade entre a cooperação dos projetistas e a composição de uma totalidade no projeto, intervindo nas atividades individuais e na 
equipe como um todo. Através da coordenação de proposições, os projetistas vão aprendendo com seus colegas o que precisa ser analisado, bem como os subsídios necessários para se definir os procedimentos metodológicos e para se tomar decisões em relação ao AVA. Deste modo, a ação de projetar um AVA acarreta uma mobilidade reversível, a qual é caracterizada pela relação entre o aspecto social (das interações interindividuais) e o aspecto lógico (das operações mentais) e pela relação entre forma e conteúdo.Tal processo pode ser visibilizado tanto no âmbito das formalizações que constituem o projeto, quanto nos procedimentos adotados para a implementação e avaliação do artefato. Um exemplo disso, é o formulário de avaliação usado para o ROODA, que é apresentado na Evidência 3.

\begin{tabular}{|c|c|c|c|}
\hline \multicolumn{4}{|l|}{ FFUNCIONALIDADE: Atividades } \\
\hline $\begin{array}{c}\text { Data } \\
\text { Problema/ Sugestão }\end{array}$ & $\begin{array}{c}\text { Prioridade } \\
1-\text { Urgente } 2 \text {-Importante } \\
3-\text { Interessante }\end{array}$ & $\begin{array}{c}\text { Dificuldade/tempo } \\
\text { Difícil Médio } \\
\text { Fácil }\end{array}$ & $O k$ \\
\hline $\begin{array}{l}\text { 14/04/05 } \\
\text { SUGESTÃO: Quarta opção de } \\
\text { atividade: Página WEB. }\end{array}$ & 1 - urgente & Fácil & $\mathrm{X}$ \\
\hline $\begin{array}{l}\text { 14/04/05 } \\
\text { PROBLEMA: Visualização de arquivo } \\
\text { pdf - o sistema avisa que o arquivo não } \\
\text { foi encontrado. }\end{array}$ & 1 - urgente & Médio & $\mathrm{X}$ \\
\hline $\begin{array}{l}25 / \mathbf{0 5 / 0 5} \\
\text { SUGESTÃO: Possibilidade de mudar a } \\
\text { ordem das atividades, para que as } \\
\text { atividades mais recentes sejam as } \\
\text { primeiras, e por consequiência, as mais } \\
\text { antigas sejam as últimas. }\end{array}$ & 2 - Importante & Fácil & $\mathrm{X}$ \\
\hline
\end{tabular}

\section{Evidência 3: Formulário de Catalogação e Classificação de Dados usada na Avaliação do ROODA}

Através da Evidência 3, vislumbra-se um dos procedimentos adotados no projeto ROODA para a avaliação do AVA, o qual foi montado para sistematizar o registro dos problemas apontados pelos usuários e projetistas e das reformulações implementadas. A Evidência 3 refere-se à funcionalidade Atividades, no entanto essa organização da tabela pautou o acompanhamento de todas as funcionalidades com os diferentes tipos de usuários. A construção desta tabela partiu da necessidade de normatizar os valores, ou seja, de estabelecer regras que orientassem as atividades do projeto no processo de avaliação do ROODA. Antes dela, as modificações eram solicitadas pelos PE aos PP e aos PD via lista de discussão ou presencialmente, de maneira aleatória, o que contribuiu para problemas de comunicação referente às escolhas realizadas pela equipe.

A partir da normatização proposta nesta tabela, superam-se as decisões subsidiadas por interesses momentâneos e trabalha-se com a premissa da obrigatoridade trazida pela regra, o que é derivado da interação entre dois ou mais projetistas e comporta composições reversíveis. Converge-se para uma reciprocidade entre os dados coletados pelos PE, a definição das prioridades e a operacionalidade da implementação, de modo que a decisão sobre uma coluna influenciava nas outras linhas e vice-versa. Por exemplo, um problema com prioridade urgente e dificuldade/tempo fácil, deveria ser implementada antes de um problema com prioridade importante e dificuldade/tempo difícil, tendo em vista as relações hierárquicas definidas pelos projetistas para essas expressões. Logo, evidencia-se uma transitividade entre os registros feitos na tabela usada para a avaliação, pois a relação da primeira informação com a segunda e da 
segunda com a terceira, acarreta uma relação da primeira informação com a terceira, interferindo nas escolhas da equipe.

Neste processo de avaliação do ROODA, as regras asseguraram uma sistematização dos valores em forma de totalidades lógicas, confluindo para certa continuidade temporal nas atividades dessa etapa de construção do AVA. Esta maneira de registro e organização dos dados coletados possibilitou que a equipe dimensionasse 0 que precisava ser feito, auxiliando na distribuição das tarefas e agilizando as trocas entre os projetistas. Também ajudou a dimensionar quais mudanças interfeririam no projeto e se elas teriam relação com outras funcionalidades. Os observáveis apontados na etapa de avaliação eram analisados e trabalhados pela equipe, que propunha melhorias a partir do projeto definido. Isto envolveu a coordenação de operações e a execução de ações, processo regido por leis de equilíbrio e que se caracteriza pela conservação das regras formais e pela reversibilidade de pensamento. Portanto, a construção do AVA requer que os projetistas operem com os observáveis apontados e com as formalizações construídas no projeto, implicando uma reflexão da ação técnica e dos procedimentos adotados pelos projetistas e uma compreensão operatória das ações materiais. Tal processo é enriquecido pela reflexão conceitual e pela construção de regras lógicas, o que envolve um debate sobre a concepção epistemológica do projeto e uma revisão dos procedimentos metodológicos.

\section{Considerações Finais}

O estudo sobre criação de novidades na ação de projetar AVAs comporta um entendimento sobre o jogo entre forma e conteúdo, bem como a compreensão por parte dos projetistas sobre as reconstruções e mudanças que constituem esse processo. Isso implica a compreenção sobre as ações da equipe e sobre as pesquisas e os debates que convergem para o levantamento de observáveis e para as escolhas dos projetistas. Tais reconstruções e mudanças remetem à interdependência entre a construção de estruturas formais nos projetistas e de formalizações para o projeto, o que pode ser vislumbrado nas transformações das regras formais que subsidiam as escolhas realizadas. Destaca-se que, quando o projetista compreende um novo observável e o leva para a equipe, pode ser gerada uma necessidade lógica nos projetistas, a qual instiga a uma revisão das generalizações e das formalizações que subsidiam o projeto. Essas generalizações e formalizações elaboradas para o projeto precisam ser compreendidas pelos projetistas, que, por sua vez, as enriquecem com novos observáveis e novas relações, conforme foi visibilizado nas evidências coletadas nos projetos do NUTED/UFRGS e apresentadas nesse artigo.

Portanto, ao elucidar a criação de novidades na ação de projetar, destaca-se as escolhas feitas pelos projetistas e os procedimentos adotados na ação de projetar. Com isso, remete-se às diferenciações e às integrações entre as propriedades do AVA e à construção de um objeto de conhecimento conceitual, o que é caracterizado pela criação de classes e subclasses para o AVA. Esse processo de criação depende da cooperação entre os projetistas, configurando uma articulação entre as operações individuais, as composições da equipe e as interações interindividuais. Assim, a partir de uma leitura embasada no estudo de caso realizado com o NUTED/UFRGS, entende-se que a criação de novidades na ação de projetar AVAs caracteriza-se: 1) pelas integrações e diferenciações entre as propriedades do objeto de estudo; 2) pela interdependência entre as estruturas formais dos projetistas e formalizações do projetos; 3) pela elaboração de nomenclaturas usadas no projeto e de composições lógicas das relações entre as 
expressões; 4) pela definição de escolhas para o projeto, e 5) pelo entendimento das mudanças no projeto a partir dos momentos de desequilíbrio e de reorganização dos observáveis.

\section{Referências Bibliográficas}

LEITE, S. M. A interdisciplinaridade na ação de projetar ambientes virtuais de aprendizagem: o caso dos projetos do NUTED/UFRGS. Porto Alegre: UFRGS, 2008. Tese (Doutorado) - Programa de Pós-Graduação em Informática na Educação, Universidade Federal do Rio Grande do Sul, Porto Alegre, 2008. Disponível em: http://hdl.handle.net/10183/16174

LEITE, S. M; BEHAR, P.; BECKER, M. L. Relações Interdisciplinares na Ação de Projetar Ambientes Virtuais de Aprendizagem.. In: XXXIII Congresso Brasileiro de Comunicação - GP Comunicação e Educação, 2009, Curitiba. XXXII Congresso Brasileiro de Ciências da Comunicação: Comunicação, Educação e Cultura na Era Digital. São Paulo : Intercom, 2009. v. 1. p. 16-31.

A construção de ambientes virtuais de aprendizagem através de projetos interdisciplinares. In: BEHAR, P. (Org.). Modelos Pedagógicos em Educação a Distância. 1 ed. Porto Alegre: Artmed, 2008, v. 1, p. 114-145.

OLIVEIRA, R. . Descobre-se o que existe, inventa-se o que não existe. In: Fernando Becker; Tania B. I. Marques. (Org.). Ser professor é ser pesquisador. Porto Alegre: Mediação, 2007, v. , p. 21-28.

Sobre o ensino de projeto: um quase-manifesto. In: Arqtexto, Porto Alegre, n. 5, p. 148-152, 2004.

PIAGET, J. Abstração Reflexionante. Porto Alegre: Artmed. 1995.

O Possível e o Necessário: Volume 1. Porto Alegre: Artes Médicas. 1985.

Tomada de Consciência. São Paulo: Editora da Universidade de São Paulo. 1977.

Problemas Gerais da Investigação Interdisciplinar e Mecanismos Comuns. 2ed. Lisboa: Livraria Bertrand, 1976.

Estudos Sociológicos. Rio de Janeiro: Forense. 1973.

YIN, R. Estudo de Caso: Planejamento e Métodos. 3ed. Porto Alegre: Bookman. 2005. 